\title{
O crescimento da área urbana da cidade de São Carlos/SP entre os anos de 2010 e 2015: o avanço da degradação ambiental
}

\author{
The growth of the urban area of São Carlos/SP between the 2010 and 2015: \\ the advancement of environmental degradation
}

Fábio Noel Stanganini [a], José Augusto de Lollo ${ }^{[b]}$

[a] Universidade Federal de São Carlos - UFSCAR, São Carlos, SP, Brasil

[b] Universidade Estadual Paulista "Júlio de Mesquita Filho" - UNESP, Ilha Solteira, SP, Brasil

\section{Resumo}

O objetivo deste trabalho foi analisar o avanço da degradação ambiental no município de São Carlos/SP em decorrência do processo de crescimento da área urbana entre os anos de 2010 e 2015. Foram abordados os seguintes aspectos: as atividades antrópicas, a degradação ambiental, o crescimento da área urbana e os impactos ambientais. Teve-se auxílio de ferramentas de análise espacial, como Sistemas de Informação Geográfica (SIG), sensoriamento remoto e cartografia digital, que permitiram a observação e o monitoramento da atual situação da área urbanizada em um nível detalhado por análise temporal. Foi detectada uma situação preocupante de crescimento desordenado, fruto de um processo disperso e desregrado sobre o solo, indicando a necessidade de maior controle e, principalmente, da efetivação de instrumentos de gestão urbana. Há indícios de que os problemas ambientais continuarão evoluindo por conta do processo de crescimento da área urbana, o que indica um potencial de degradação em áreas ainda não afetadas.

Palavras-chave: Degradação ambiental. Crescimento urbano. Geoprocessamento. Planejamento urbano. Impactos ambientais.

\section{Abstract}

The objective of this study was to analyze the progress of environmental degradation in the municipality of São Carlos, Sao Paulo state, as a result of the urban area growth process between 2010 and 2015. The following aspects were addressed: the anthropogenic activities that caused environmental degradation and the urban area growth and its relation to environmental impacts. To this end, spatial analysis tools such as Geographic Information Systems (GIS), remote sensing, and digital cartography were used, enabling temporal analysis through detailed observation and monitoring of the urban area current situation. An alarming situation of uncontrolled growth was detected, which is a result of a disperse and unregulated process on the soil, highlighting the need for better control of this process and, mainly, for implementation of urban management tools. There are indications that the environmental problems will continue to evolve as a result this urban area growth process, which indicates a potential for degradation of areas not yet affected.

Keywords: Environmental degradation. Urban growth. Geoprocessing. Urban planning. Environmental impacts.

FNS é doutor em Engenharia Urbana, e-mail: fnsgeo@gmail.com

JAL é professor titular, e-mail: ja_lollo@yahoo.com 


\section{Introdução}

Os problemas relacionados à degradação ambiental são relativamente associados com alterações do ecossistema por causa do desenvolvimento econômico, do crescimento desordenado das cidades e, principalmente, da mudança de uma sociedade rural para uma sociedade urbana em um curto período de tempo, sobretudo em países cujo processo de desenvolvimento foi tardio.

A intensificação do processo de urbanização é considerada como um dos grandes indutores dos atuais problemas ambientais devido à diversificação de usos da terra, à degradação dos solos, à retirada da vegetação etc. A literatura sobre a questão urbana no Brasil indica que a expansão das áreas periféricas está relacionada à procura por habitação em áreas com baixo preço da terra, provocando um aumento das ocupações precárias, como favelas e loteamentos irregulares, em áreas sem infraestrutura e expostas a riscos (Bonduki \& Rolnik, 1982; Smolka, 1993; Maricato, 1996).

Parte dos problemas é relacionada ao ritmo de crescimento das cidades médias brasileiras ao longo dos anos, o que exprime claramente a aceleração do processo de urbanização que teve início nas décadas de 1950 e 1960. Com isso, não surpreende a constatação de que, na década de 1970, os municípios com população superior a 100 mil habitantes chegavam a 70, enquanto, em 1991, apenas 21 anos depois, esse número evoluiu para 185, segundo os dados do IBGE de 2013. Atualmente, em torno de 300 municípios têm população acima de 100 mil habitantes, dos quais 69 são de médio porte localizados no Estado de São Paulo.

0 acelerado processo de crescimento das cidades médias nas últimas décadas tem motivado estudos relacionados à gestão, ao planejamento e ao ordenamento territorial. A fim de alcançar o crescimento de forma sustentável, conciliando o crescimento urbano e o desenvolvimento econômico, as técnicas e os produtos compreendidos pelos sistemas de informações geográficas, cartografia digital e sensoriamento remoto têm sido um grande aliado ao desafio de planejar e ordenar o espaço urbano e seu entorno, proporcionando subsídios técnicos para a tomada de decisão dos planejadores e gestores.

Segundo Santos (2007), a forma como é feita a ocupação do espaço tem provocado sucessivos e inúmeros problemas ambientais, como degradação da cobertura vegetal, perda de biodiversidade, obstrução e alteração da rede de drenagem, transmissão de doenças de veiculação hídrica, contaminação e poluição do ar, da água e do solo, perda de terras produtivas, desencadeamento de processos erosivos, entre outros.

O desconhecimento, por parte do poder público, dos condicionantes do meio físico em áreas de expansão urbana favorece o surgimento de impactos ambientais e a degradação do meio. Tais resultados se manifestam na forma de impactos socioambientais, inundações, erosões, assoreamento dos corpos d'água e falta de recursos hídricos em um futuro próximo, como observado em algumas regiões do Estado de São Paulo em 2014.

Ao longo dos anos, o município destaca-se como objeto de estudos que apontam para a questão da degradação ambiental, associada ao crescimento da área urbana, à expansão urbana desordenada, à falta de infraestrutura urbana, ao ordenamento e à ocupação de novas áreas, conforme apontam Zuquette (1987) e Blum (1998).

O estudo da evolução do processo de crescimento da área urbana do município de São Carlos no Estado de São Paulo, entre os anos de 2010 e 2015, indica a clara necessidade de melhorar o diagnóstico e o prognóstico, bem como planejar as ações de ocupação e ordenamento do território de forma mais adequada.

Levantamentos recentes daárea de estudo demonstram que são necessários o máximo de informações e a elaboração de planos para implantação de projetos que visem controlar o processo de crescimento e a degradação ambiental.

Diante de tais questões, o trabalho buscou reconhecer a atual situação das áreas degradadas no município de São Carlos/SP e fornecer subsídios técnicos para o planejamento urbano ambiental por meio da comparação entre os anos de 2010 e 2015 envolvendo o crescimento da área urbana.

\section{Área de estudos}

O município de São Carlos está localizado na Região Administrativa Central do Estado de São Paulo, com população urbana de 241.389 mil habitantes, área total de 1.136,907 $\mathrm{km}^{2}$ e área urbana atual de $102,70 \mathrm{~km}^{2}$ (IBGE, 2015). A área de estudos do trabalho compreende um raio de $350 \mathrm{~km}^{2}$, com destaque para 
a área urbanizada do município como ponto central. A Figura 1 demonstra a área do município e o local em que o trabalho foi desenvolvido.

Nas últimas décadas, o município de São Carlos tem passado por um processo rápido e desordenado de crescimento da área urbana, direcionado, principalmente, em razão da valorização imobiliária de áreas privilegiadas, ocorrendo de forma claramente não planejada, o que agrava e potencializa os problemas ambientais já existentes, tanto no entorno direto como no entorno indireto.

Destaca-se que os dois grandes eixos de expansão de São Carlos foram conduzidos para as regiões norte, e uma parcela de um eixo, para a região sul, sendo a última inserida em áreas ambientalmente frágeis pelo tipo de solo ali presentes. Estudos apontam que a localidade tem alto grau de vulnerabilidade, e o processo tem sido intensificado nos últimos anos nessa região. Elementos demonstram o elevado nível de degradação ambiental, localizadas nas franjas urbanas, carente de infraestrutura e de suporte técnico para ocupação.

Para autores, como Gonçalves (1986), Gaspar (2000) e Pons et al. (2007), no município de São Carlos, os principais problemas encontrados são: despejo de esgoto in natura nos rios, supressão de vegetação nativa e de áreas de preservação permanente, falta de áreas verdes, falta de locais adequados para despejo de resíduos, processos erosivos, assoreamento de córregos e rios, entre outros distúrbios, que têm sido potencializados pela rápida urbanização.

Fatores, como a regulação insuficiente e a falta de fiscalização nas últimas décadas, possibilitaram a intensa ocupação de áreas de várzea, implantação de novos conjuntos habitacionais e crescimento das áreas com maior grau de impermeabilização do que o permitido pela lei.

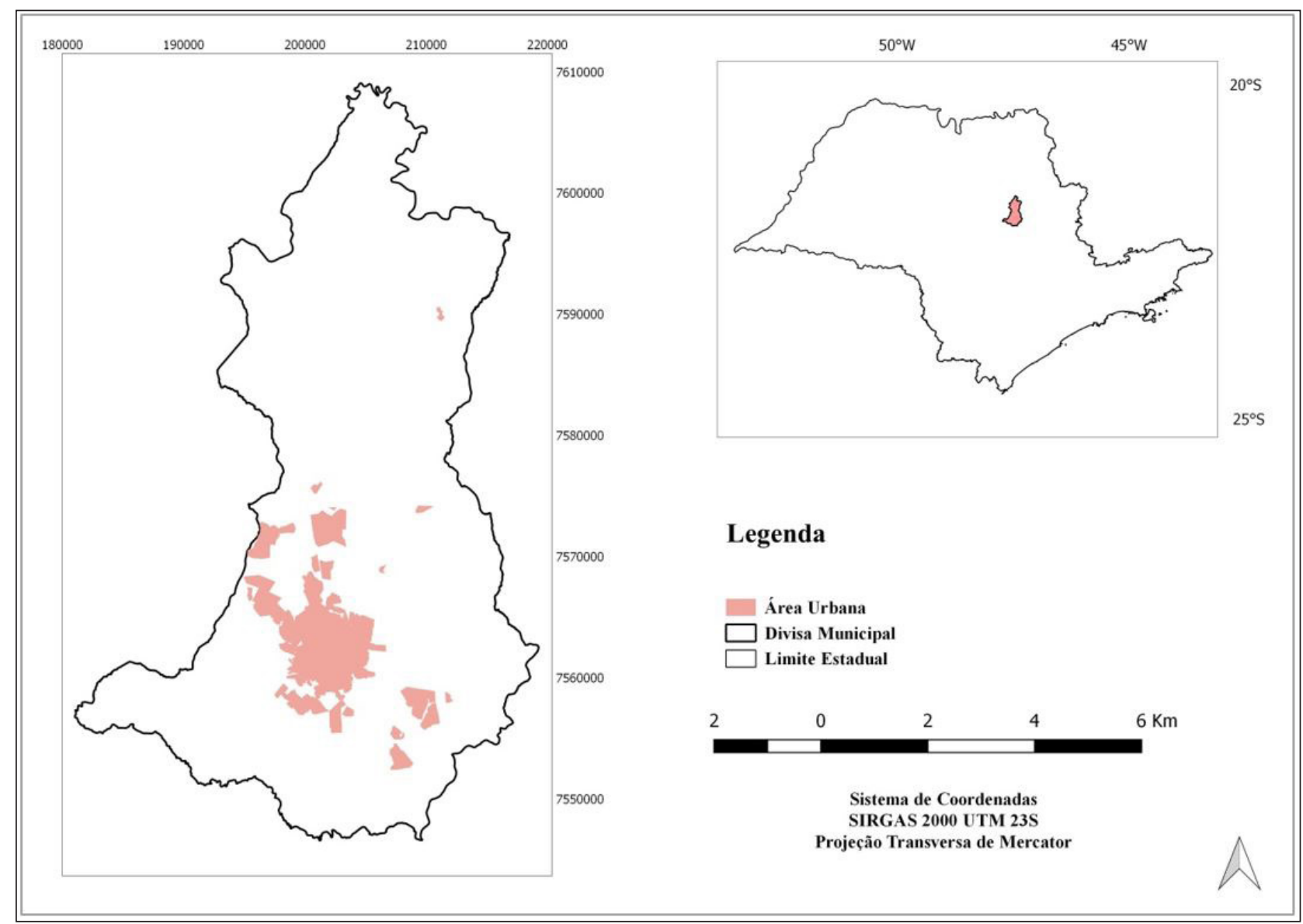

Figura 1 - Localização da área de estudo Fonte: autores (2017). 


\section{Materiais e métodos}

$\mathrm{Na}$ construção do trabalho, foram utilizados diferentes produtos e técnicas, sendo: base de dados do IBGE contendo os shapefiles da área urbana, hidrografia, redes de circulação (ruas e rodovias), dados do Censo Demográfico e imagens do satélite LANDSAT- 5 e 8 dos anos de 2010 e 2015.

Os dados foram integrados, armazenados e tratados em SIG (Sistema de Informação Geográfica) livre, o QGIS 2.14, versão Essen (Quantum GIS Development Team, 2015). A projeção utilizada foi a UTM, com Datum Horizontal SIRGAS 2000 e Zona 23 Sul. A primeira etapa da construção foi a obtenção das imagens, a utilização de técnicas de processamento e de georreferenciamento e a classificação não supervisionada.

Na segunda etapa, foram construídas as classes de uso (1 - área urbana, 2 - vegetação, 3 - solo exposto, 4 - área agrícola e 5 - hidrografia), o mapeamento em uma escala de 1:50.000, as correções de polígonos dentro do ambiente SIG e, por conseguinte, a interpretação das imagens.

A terceira etapa incluiu a mensuração temporal das imagens e a classificação entre as classes e os percentuais de perda de vegetação entre 2010 e 2015, assim como os percentuais de crescimento da área urbana e de outras classes.

A quarta etapa do trabalho foi relacionada à interpretação dos dados elaborados, geração de mapas temáticos, discussões, resultados e propostas.

Foram utilizados os seguintes produtos cartográficos: a) carta topográfica do município de São Carlos de 1971; b) Imagens Thematic Mapper - TM LANDSAT 5 e 8 sensor Operational Land Imager (OLI), sendo as bandas espectrais do TM: 3 (vermelho), 4 (infravermelho) e 5 (infravermelho-médio), com resolução espacial de $30 \mathrm{~m}$; c) dados de shapefile do município de São Carlos, da área urbana e do recorte da área de estudos; d) dados de shapefile da rede hidrográfica, das rodovias e das ferrovias.

Os materiais cartográficos, que constam no Quadro 1, como carta topográfica, zoneamento urbano, loteamentos e eixo de ruas e escalas de trabalho, foram analisados segundo a classificação proposta por Zuquette (1987): escalas menores que 1:100.000 representam escalas gerais; as de 1:100.000 a 1:25.000 são escalas regionais; e as de 1:25.000 a 1:10.000 são escalas de semidetalhe. Neste trabalho, foram utilizadas as escalas de 1:50.000 e 1:60.000.

\section{Resultados e discussões}

0 crescimento das cidades brasileiras nas últimas décadas tem causado o aumento da degradação ambiental nas áreas urbanas. Esse rápido crescimento trouxe enorme pressão sobre os recursos naturais, ocasionando uma elevada demanda por serviços e por uma infraestrutura urbana adequada do ponto de vista ambiental.

Os problemas relacionados aos impactos ambientais do processo de urbanização e, principalmente, à rápida mudança econômica das cidades, sobretudo em países cujo processo de desenvolvimento foi tardio, afetam sobremaneira os recursos naturais. Muitas vezes, esse modelo urbanístico predatório é motivado por interesses privados em detrimento dos sociais, desrespeitando as diretrizes de crescimento do município, as normas de loteamento e as áreas de preservação permanente (Rolnik, 2009).

As mudanças recentes na composição das cidades brasileiras apontam para um conjunto de problemas e consequências ambientais comuns entre os municípios, destacando-se as questões relacionadas ao uso e à ocupação da terra, à mobilidade urbana e ao saneamento ambiental, que acabam tendo maior potencialização pela rápida urbanização.

\section{Quadro 1 - Material cartográfico}

\begin{tabular}{|c|c|c|c|c|}
\hline Cartas & Cidades & Referências & Fonte & Escala \\
\cline { 1 - 3 } Topográficas & São Carlos & SF-23-Y-A-t- & \multirow{2}{*}{ IBGE (1971) } & 1:50.000 \\
\cline { 2 - 3 } & Ibaté & SF-23-V-C-IV-3 & São Carlos (2014a, 2014b) & $1: 60.000$ \\
\hline Zoneamento & São Carlos & & \\
\hline
\end{tabular}

Fonte: IBGE (1971) e Prefeitura Municipal de São Carlos (2014a, 2014b). 
Fruto desse contexto, ao longo das últimas décadas, as cidades brasileiras de médio porte (acima de 200 mil habitantes) vêm apresentando graves problemas ambientais. A maioria dos municípios possui características semelhantes no que tange ao modelo de urbanização, sendo disperso, fragmentado, com exclusão social e segregação espacial, com ausência de infraestrutura em determinadas áreas em detrimento de outras e uso intensivo de recursos naturais.

As cidades consideradas médias no Estado de São Paulo são palco desse processo, em que o desenvolvimento econômico pressupõe o desenvolvimento sustentável e social, abarcando grande parte desses problemas, frutos da falta de organização urbana das respectivas áreas, sendo encontrado no município objeto de estudo (São Carlos).

Durante o período analisado, as mudanças ocorridas foram significativas e impactantes, principalmente no que tange às ocupações pelo processo de urbanização e ao aumento da área de solo exposto e áreas agrícolas, evidenciando que, na urbanização do município, no período de cinco anos, sua área urbana cresceu significativamente, sobretudo a partir do ano 2000, com a intensa massificação de condomínios e loteamentos de classes A e B, ditos de "alto padrão" e "fechados", além de conjuntos habitacionais direcionados à população de baixa renda.

0 Quadro 2 exemplifica o processo de crescimento populacional e o grau de urbanização do município de São Carlos entre os anos de 1980 e 2015, demonstrando que, em sua maioria, as cidades médias aumentaram de tamanho e de população ao longo dos anos com o mesmo modus operandi, ou seja, sem um modelo que organize o crescimento e a expansão.
Os dados relativos aos períodos anteriores indicam parte desse crescimento. Em 1980, o município possuía $37,74 \mathrm{~km}^{2}$ de área urbana, conforme dados obtidos por meio das imagens de satélite, e uma população, segundo Censo do IBGE, de 119.535 mil habitantes. Já na década de 1990, a área urbana era de $38,86 \mathrm{~km}^{2}$, e a população, de 158.221 mil habitantes; ou seja, a área urbanizada cresceu em torno de $11,21 \mathrm{~km}^{2}$ e a população teve um aumento de 38.686 mil habitantes. No período destacado, enquanto a área urbanizada cresceu pouco mais de $10 \%$, a população cresceu quase $35 \%$.

Esse intenso processo de urbanização, rápido e desordenado, acarretou impactos representativos para o meio urbano do município. Entre as décadas de 1970 e 1980, houve um aumento significativo nas inundações, decorrente do aumento de áreas impermeabilizadas, assim como escoamento superficial, o que desencadeou o processo de canalização de alguns córregos, como o do Gregório.

Mendiondo \& Mendes (2007) já relacionavam o processo de ocupação e crescimento da área urbanizada, o processo de impermeabilização rápida das sub-bacias do Monjolinho e do Gregório de 1940 a 2004 e suas reais consequências e relações com as inundações na área urbana, principalmente com o aumento das ocorrências durante o período analisado, demonstrando que o processo foi certamente o grande agravante do aumento dos impactos ambientais.

Dupas (2001) aponta que o município de São Carlos expandiu sua área urbanizada (mancha urbana) sem contabilizar fatores ambientais, como geologia, pedologia, uso da terra, erosão, assoreamento, urbanização, entre outros fatores, desconsiderando também os interesses da população no processo de crescimento.

Quadro 2 - Grau de urbanização do município de São Carlos (SP)

\begin{tabular}{|c|c|c|c|c|}
\hline & Ano & $\begin{array}{c}\text { Grau de } \\
\text { urbanização (\%) }\end{array}$ & $\begin{array}{c}\text { População } \\
\text { urbana }\end{array}$ & $\begin{array}{c}\text { Área urbanizada } \\
\text { em km }^{\mathbf{2}}\end{array}$ \\
\hline \multirow{4}{*}{$\begin{array}{c}\text { Dados do Censo do IBGE e da } \\
\text { Prefeitura Municipal }\end{array}$} & 1980 & 92,21 & 119.535 & 36,45 \\
\cline { 2 - 5 } & 1990 & 93,66 & 153.762 & 38,90 \\
\cline { 2 - 5 } & 2000 & 95,04 & 192.565 & 60,01 \\
\cline { 2 - 5 } & 2010 & 95,99 & 221.950 & 80,82 \\
\cline { 2 - 5 } & 2015 & 97,56 & 241.389 & 102,70 \\
\hline
\end{tabular}

Fonte: elaborado pelos autores (2016). 
Molina (2003) afirma que, entre 1962 e 2002, a área urbanizada do município teve uma expansão para o sul e noroeste, atingindo o Rio Monjolinho e o Córrego da Água Quente, o que acabou interferindo e modificando alguns trechos dos corpos hídricos, afetados pelo aumento de técnicas de canalização, assim como a perda de nascentes e de olhos d'água por soterramentos e pela implantação de loteamentos.

Atualmente, segundo os últimos dados do censo, o município de São Carlos possui uma população de 241.389 mil habitantes, situando-se na região central do Estado de São Paulo. Por causa dessa condição geográfica e da proximidade das vias de acesso entre os municípios de Ribeirão Preto e Araraquara, é possível grande facilidade na circulação de mercadorias e de transporte; logo, a cidade de São Carlos tem um importante papel regional, principalmente nas cidades circunvizinhas e nos municípios de pequeno porte.

A trajetória de evolução da urbanização do município nos últimos 35 anos (Quadro 2) tem sido um grande desafio ao processo de ordenamento territorial versus conservação ambiental versus preservação ambiental. 0 avanço desordenado da área urbana, principalmente em direção à Rodovia Washington Luiz e à Rodovia Engenheiro Thales de Lorena Peixoto Júnior, vem sendo o principal eixo de expansão urbana e crescimento da cidade (no sentido norte, o eixo dessas rodovias e cidades).

O modelo adotado no município provocou perdas e impactos no meio ambiente sem precedentes, como destruição de nascentes, assoreamento dos corpos d'água, erosão, maior vulnerabilidade a regiões de recarga do aquífero, alagamentos, inundações, aumento de temperatura, ocasionada pelo crescimento da área impermeabilizada, e supressão da vegetação nativa (áreas de preservação permanente).

Outro fator preponderante é a perda da vegetação nativa. A Figura 2 representa a classe de uso vegetação e a respectiva área urbana de 2010 e 2015. 0 Quadro 3 apresenta o crescimento da área urbana e a perda de

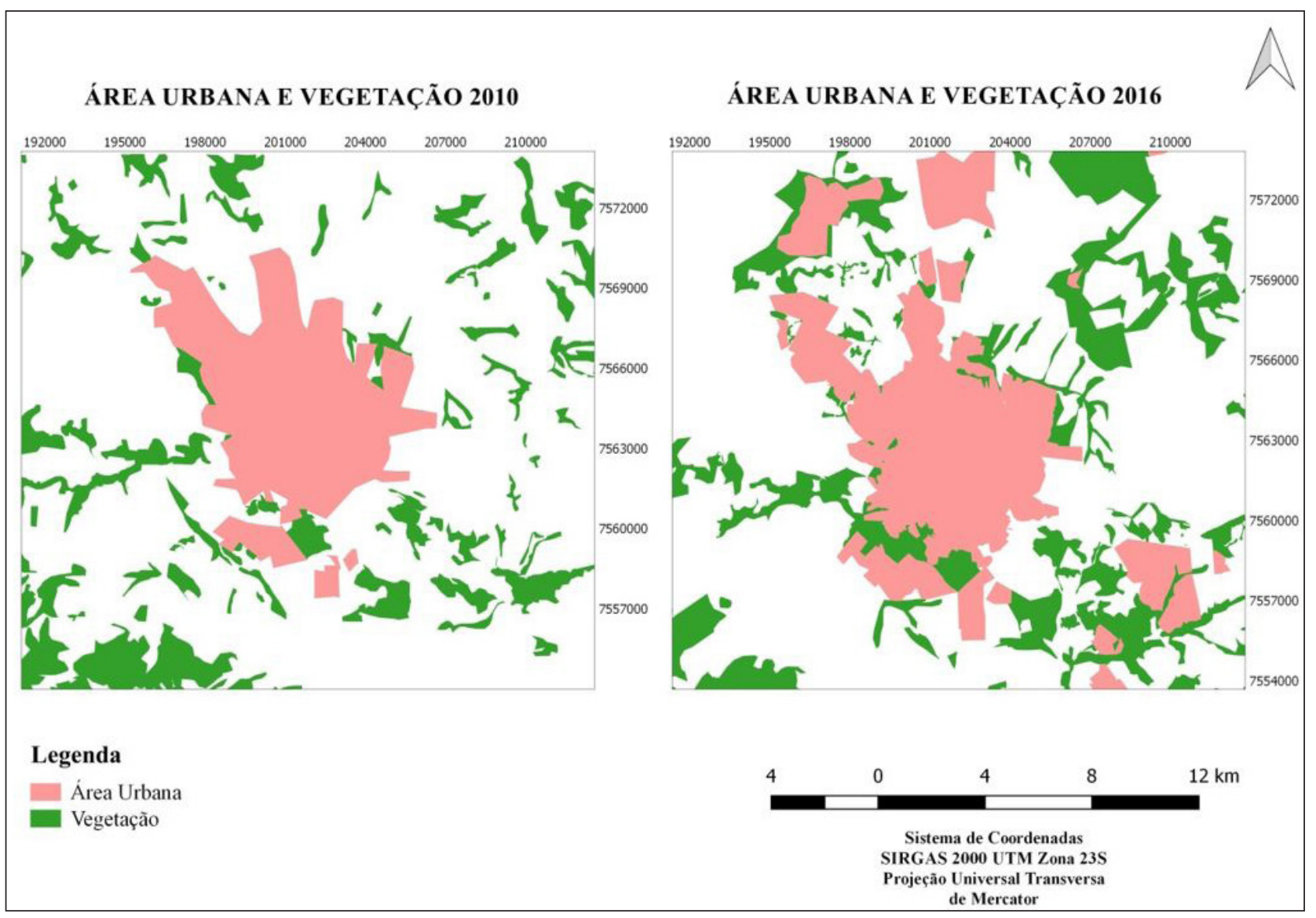

Figura 2 - Área urbana versus área de vegetação de 2010 e 2016 Fonte: autores (2017). 
Quadro 3 - Crescimento da área urbana e perda de vegetaç̃a em km²

\begin{tabular}{|c|c|c|}
\hline Classe de uso & $\mathbf{2 0 1 0}$ & $\mathbf{2 0 1 5}$ \\
\hline Vegetação & 78,15 & 52,95 \\
\hline Área urbana & 80,82 & 102,70 \\
\hline
\end{tabular}

Fonte: elaborado pelos autores (2016).

vegetação no período. 0 uso de imagens e de técnicas de interpretação auxiliou na construção da análise de perda da vegetação durante o período, totalizando, aproximadamente, $25,2 \mathrm{~km}^{2}$ de área.

A expansão urbana sempre teve um caráter extremamente econômico, não considerando as barreiras e as limitações do meio físico, características que deveriam limitar e impedir o crescimento da cidade direcionado para determinadas áreas e regiões ambientalmente frágeis e vulneráveis.

Segundo Schenk et al. (2015), os atuais desdobramentos desse processo convivem com uma tendência diametralmente oposta, isto é, a produção de espaços residenciais privilegiados, também em áreas geograficamente periféricas, destinados, agora, às camadas de alto poder aquisitivo, separados territorialmente do resto da cidade.

Fica evidenciado, na trajetória do processo de crescimento da cidade, que as áreas com melhor potencial e acesso sempre foram destinadas à construção do grande capital imobiliário, por meio de condomínios, loteamentos e residenciais de alto padrão, enquanto as piores áreas sempre foram associadas às moradias de baixa renda, espaçando a noção de exclusão e de privilégios.

A expansão físico-territorial da cidade teve como lógica uma ocupação pautada pela implantação de loteamentos em áreas descontínuas que beneficiavam os interesses dos grandes donos de terras e a atuação especulativa do mercado imobiliário. Esse tipo de expansão caracterizou-se por um momento de aumento significativo da população e expansão descontínua de loteamentos populares rumo à periferia.

Nesse período, consolidou-se um processo de expansão urbana no qual prevaleceu a produção do chamado "padrão periférico" - desprovido de infraestrutura ou com infraestrutura precária - com atuação do poder público atrelado ao setor imobiliário (RPDMSC, IAU / São Carlos, 2014a, p. 53).
A Figura 2 representa que a área urbana teve um aumento considerável em um curto período de tempo, passando de $80,82 \mathrm{~km}^{2}$ em 2010 para $102,70 \mathrm{~km}^{2} \mathrm{em}$ 2015; logo, o atual processo de crescimento nesse período indica um avanço no crescimento da área urbana.

A análise do processo de crescimento da área urbanizada de São Carlos indica que, anteriormente às décadas estudadas, os fundos de vale, como os Córregos do Tijuco Preto, Monjolinho e Gregório, tiveram seu processo de ocupação acelerado entre os anos de 1940 e 1970, aumentando gradativamente durante o período de 1990 a 2010, o que caracteriza o processo de expansão urbana, que continua pressionando os condicionantes ambientais, os recursos naturais e os recursos hídricos.

0 uso e a cobertura da terra nesses ecossistemas têm um papel fundamental para o processo de construção do ambiente, influenciando a diversidade biológica, climática e os ciclos biogeoquímicos da água. A retirada da mata ciliar, por sua vez, pode resultar em aumento da temperatura do solo, da erosão, assoreamento dos mananciais, modificações do balanço hídrico e da disponibilidade de nutrientes (Tucci \& Bertoni, 2003).

Ao longo das últimas décadas, o município tem recebido importantes investimentos e aportes financeiros de construtoras para elaboração de loteamentos e condomínios fechados. Esse processo de ocupação torna-se evidente nas entradas da cidade, quando se observa o mapa de uso e ocupação da terra (Figura 3), refletindo, por sua vez, no aumento das áreas ocupadas próximas aos rios e à vegetação, trazendo problemas em períodos de chuva por inundações. Além disso, outro dilema evidenciado neste trabalho diz respeito à observação de uma excessiva retirada das áreas de preservação permanente e da ocupação das margens dos rios para construção de ruas.

Esse cenário ocasiona uma cadeia de impactos ambientais, tais como impermeabilização do solo, alterações na topografia, erosão das margens, assoreamento dos cursos d'água, perda das matas ciliares, diminuição da biodiversidade, aumento do escoamento superficial, inundações, aumento nos congestionamentos, entre outros.

A implantação de áreas urbanas tem variadas consequências, das quais uma das mais diretas é a impermeabilização, que provoca a diminuição da capacidade de infiltração e, logo, o aumento do escoamento superficial, fator que tem grande influência no aumento das inundações no meio 


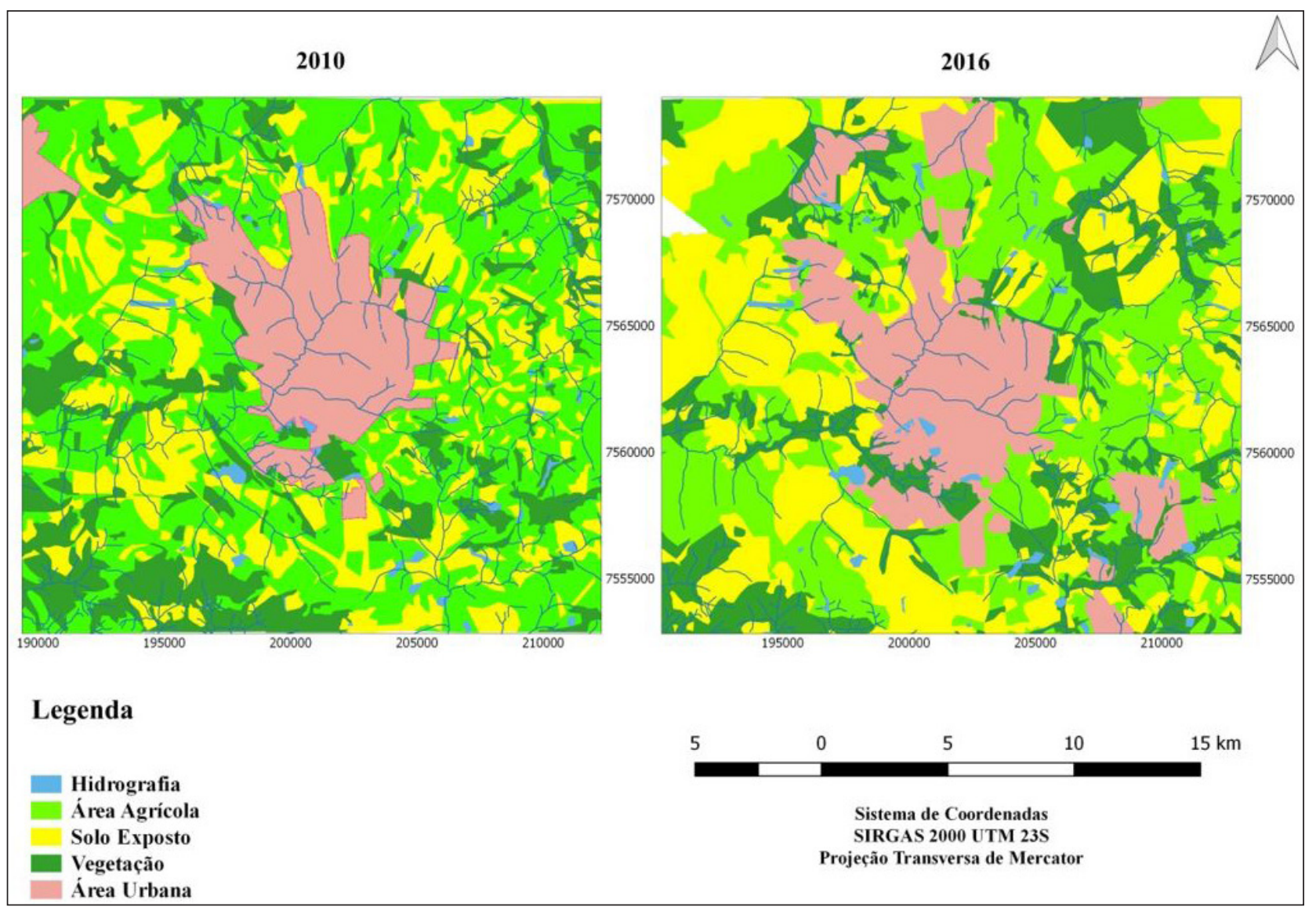

Figura 3 - Mapa do uso e da ocupação da terra de 2010 e 2016

Fonte: autores (2017).

urbano. Normalmente, para o dimensionamento das redes de drenagem, são considerados períodos de retorno de 5 ou 10 anos, mas, na ocorrência de eventos extremos, a capacidade de infiltração será menor que a intensidade de precipitação. Por isso, os solos permeáveis vão ter um comportamento diferente, tornando-se impermeáveis (Matos, 2000).

Dessa maneira, o uso da terra está intimamente relacionado à degradação do ambiente pelas ações antrópicas, tanto diretas quanto indiretas. Segundo Christofoletti (1999, p. 158), "o conceito de recursos naturais é sensível ao contexto no qual é utilizado". A Figura 4 representa a evolução da área urbana sobre aspectos, unidades de sub-bacias e condicionantes ambientais.

Os componentes existentes na superfície terrestre não surgem como recursos naturais apenas porque se encontram no sistema da natureza. Passam a essa categoria quando ganham relevância em função da intervenção humana, pelo conhecimento de sua existência, pelo conhecimento de como pode ser tecnicamente utilizado e pela sua integração a determinadas necessidades da sociedade (Christofoletti, 1999).

As informações obtidas ao longo deste trabalho sobre a degradação ambiental decorrente do uso e da ocupação desordenada mostram que na área existem problemas ambientais advindos de diferentes questões, tais como habitacionais, de impermeabilização do solo, da supressão da vegetação, de inundações etc.

Os atributos naturais não foram considerados no processo de desenvolvimento e expansão urbana; pelo contrário, a cidade cresceu negando os fundos de vale, as várzeas alagáveis, canalizando seus córregos, implantando avenidas marginais em áreas de preservação da vegetação, assentando sua tipologia viária em descompasso com as condições topográficas e seguindo o modelo rodoviarista, centrado no transporte individual. Tais características fizeram com que se ampliassem áreas de inundações e diversas condições inadequadas de uso e ocupação do solo, 


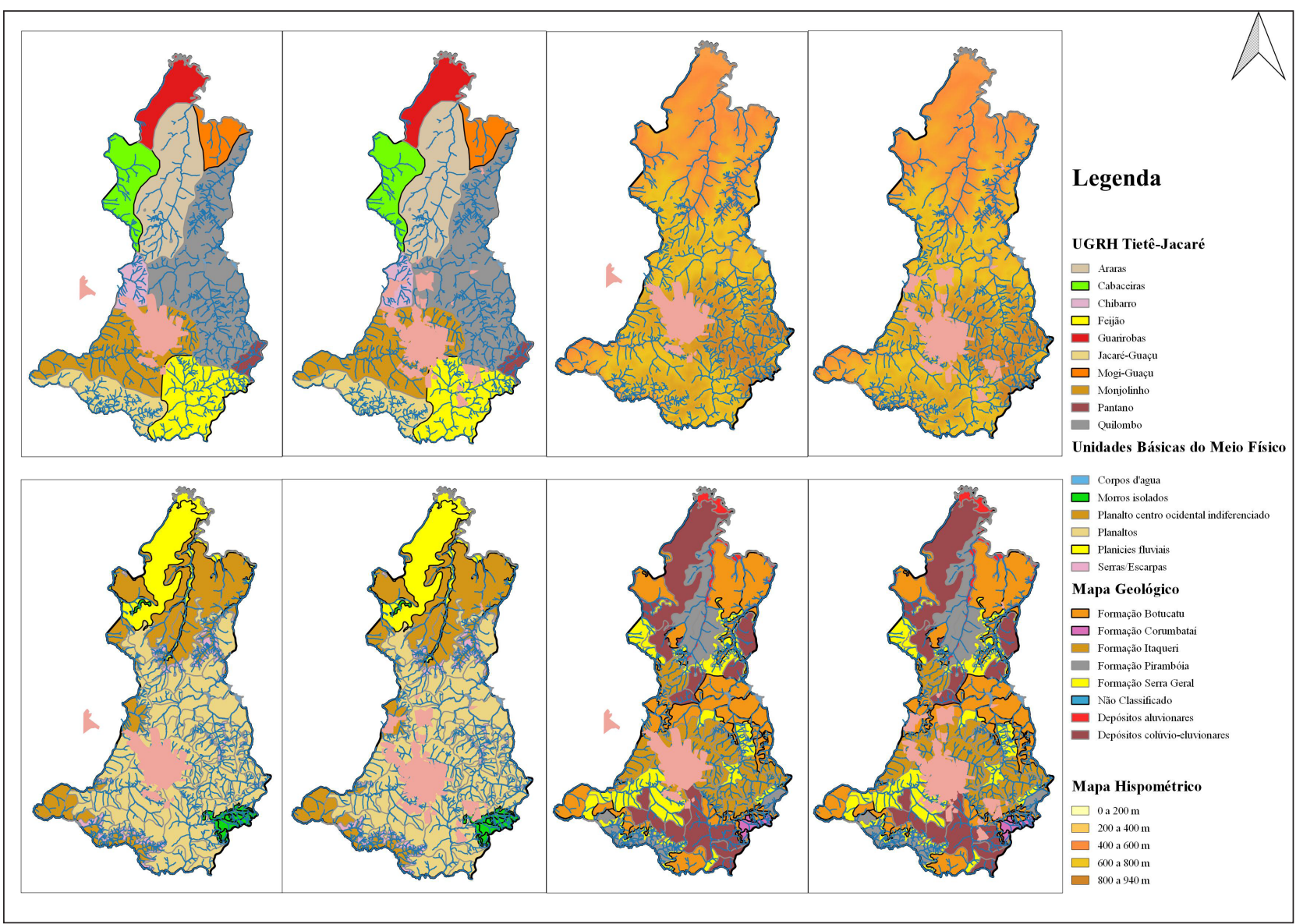

Figura 4 - Aspectos ambientais e evolução da área urbana entre 2010 e 2016 Fonte: autores (2017).

atestando aquilo que a historiografia da paisagem já consolidou como invisibilidade dos rios urbanos (Spirn, 1995; Hough, 1998).

A falta de conhecimento sobre os solos e suas funções, a ausência de planejamento, a prioridade dada aos objetivos econômicos de curto prazo, em detrimento dos objetivos ecológicos de longo prazo, o crescimento desordenado e anárquico das periferias urbanas, enfim, tudo isso contribui para a redução do capital de solos e da qualidade de vida das cidades (Beaud et al., 1995).

\section{Conclusões}

O trabalho apresenta um processo que vem ocorrendo ao longo de décadas no município de São Carlos, com a degradação ambiental surgindo em função do crescimento desordenado e da falta de políticas de planejamento urbano e ambiental. Foi possível elencar alguns aspectos de grande relevância por meio da análise histórica de cinco anos do processo de crescimento, permitindo, dessa forma, compreender que não apenas o processo de degradação, mas o movimento de utilização do espaço degradado passa a retroalimentar o processo e a atingir novas áreas.

Tal situação mostra que as políticas econômicas têm prevalecido em detrimento do processo de desenvolvimento sustentável, evidenciando a importância de considerar as relações entre o poder público e o capital privado. Outro aspecto de grande importância é que as áreas com melhor infraestrutura tendem a ser utilizadas para instalação de loteamentos de alto padrão, e locais com infraestruturas mais precárias, a ser utilizadas para a construção de conjuntos habitacionais de baixa renda.

Os resultados mostram ainda que os espaços degradados não recebem incentivos, como planos, gestões ou políticas públicas, para recuperação e melhoria de suas infraestruturas. 


\section{Referências}

Beaud, M., Beaud, G., \& Bouguerra, M. (1995). Estado do ambiente no mundo (A. M. Novaes, trad.). Lisboa: Instituto PIAGET. pp. 86-91.

Blum, W. (1998) Basic concepts: degradation, resilience, and rehabilitation. In L Rattan, WEH Blum, C Valentin, BA Stewart (ed.), Methods for assessment of soil degradation (Advances in Soil Science, pp. 1-16). Boca Raton: CRC Press.

Bonduki, N., \& Rolnik, R. (1982). Periferia da grande São Paulo: reprodução do espaço como expediente de reprodução da força de trabalho. In E. Maricato (ed.), A produção capitalista da casa (e da cidade) do Brasil industrial (pp. 154-177). São Paulo: Alfa Ômega.

Christofoletti, A. (1999). Modelagem de sistemas ambientais. São Paulo: Blücher.

Dupas, F. A. (2001). Crescimento urbano e suas implicações ambientais: proposta de redirecionamento de cidades de médio porte utilizando as variáveis ambientais, sensoriamento remoto e sig: estudo do caso de São Carlos (Dissertação de mestrado). Universidade Federal de São Carlos, São Carlos.

Gaspar, W. J. (2000). Análise do processo erosivo do loteamento social Antenor Garcia: proposta para expansão do bairro (Dissertação de mestrado). Universidade Federal de São Carlos, São Carlos.

Gonçalves, A. R. L. (1986). Geologia ambiental da área de São Carlos (Tese de doutorado). Universidade de São Paulo, São Paulo.

Hough, M. (1998). Naturaleza y ciudad - planificación urbana y procesos ecológicos. Barcelona: Gustavo Gili.

Instituto Brasileiro de Geografia e Estatística - IBGE. (1971). Cartas topográficas (Folhas SF 23-Y-A-I- 1, SF-23Y-A-I-2, SF-23-V-C-IV-3, SF-23-V-C-IV-4, Escala 1:50.000). Rio de Janeiro: IBGE.

Instituto Brasileiro de Geografia e Estatística - IBGE. (2015). Rio de Janeiro: IBGE. Recuperado em 30 de agosto de 2016, de http://www.ibge.com.br.

Maricato, E. (1996). Metrópole na periferia do capitalismo (1a ed., 141 p.). São Paulo: Hucitec.

Matos, M.R., (2000). Gestão integrada de águas pluviais em meio urbano visão estratégica e soluções para o futuro (pp. 23-26). Lisboa: LNEC.
Mendiondo, E., \& Mendes, H. (2007). Histórico da expansão urbana e incidência de inundações: o caso da Bacia do Gregório, São Carlos. Revista Brasileira de Recursos Hídricos., 12(1), 17-27. http://dx.doi.org/10.21168/ rbrh.v12n1.p17-27.

Molina, V. E. Jr., (2003). Recursos hídricos superficiais da área urbana e de expansão da cidade de São Carlos, SP - Estudo multitemporal (Dissertação de mestrado). Universidade Federal de São Carlos, São Carlos.

Pons, N. A. D., Pejon, O. J., \& Zuquette, L. V. (2007). Use of geoprocessing in the study of land degradation in urban environments: the case of the city of São Carlos, state of São Paulo, Brazil. Environmental Geology, 53(4), 727-739. http://dx.doi.org/10.1007/s00254-007-0685-y.

Quantum GIS Development Team. (2015). Guia do utilizador do QGIS. Recuperado em 15 de outubro de 2015, de http:// www.qgis.org/pt_PT/docs/user_manual/

Rolnik, R. (2009). La democracia em el filo de la navaja: limites y posibilidades para la implementación de uma agenda de reforma urbana en Brasil. Revista Eure, XXXV(104), 5-28.

Santos, C. Z. (2007). Alterações socioambientais na bacia hidrográfica do ribeirão do Lajeado no município de Paraibuna - SP (Dissertação de mestrado). São José dos Campos: Instituto de Pesquisa e Desenvolvimento, Universidade do Vale do Paraíba.

São Carlos. Prefeitura Municipal. (2014a). Mapa de fragmentos de vegetação remanescente. In: São Carlos. Prefeitura Municipal. Revisão do plano diretor de São Carlos - plano diretor estratégico. São Carlos: Prefeitura Municipal.

São Carlos. Prefeitura Municipal. (2014b). Mapa de vulnerabilidades Ambientais. In: São Carlos. Prefeitura Municipal. Revisão do plano diretor de São Carlos - plano diretor estratégico. São Carlos: Prefeitura Municipal.

Schenk, L. M. B., Fantin, M., \& Peres, R. B. (2015). A revisão do plano diretor da cidade se São Carlos e as novas formas urbanas em curso. In Anais do X Colóquio Quapá-SEL: produção e apropriação dos espaços livres e da forma urbana (pp. 1-19). Brasília: Fauunb.

Spirn, A. (1995). O Jardim de Granito, a natureza no desenho da cidade. São Paulo: Edusp. 
Smolka, M. (1993). Meio ambiente e estrutura urbana. In G. Martine (ed.), População, meio ambiente e desenvolvimento: verdades e contradições. Campinas: Editora da Unicamp.

Tucci, C., \& Bertoni, J. (2003). Inundações urbanas na América do Sul. Porto Alegre: ABRH. Recuperado em 30 de junho de 2016, de https://www.cepal.org/samtac/ noticias/documentosdetrabajo/5/23335/inbr02803.pdf
Zuquette, L. V. (1987). Análise crítica da cartografia geotécnica e proposta metodológica para condições brasileiras (Tese de doutorado). Escola de Engenharia de São Carlos, Universidade de São Paulo, São Carlos.

Recebido: Nov. 17, 2017

Aprovado: Abr. 18, 2018 